\title{
1 ANALYSIS OF IMMUNE ESCAPE VARIANTS FROM ANTIBODY-BASED THERAPEUTICS AGAINST \\ 2 COVID-19.
}

4 Daniele Focosi ${ }^{1, \#}$

$5 \quad$ Fabrizio Maggi ${ }^{2,3}$

6 Massimo Franchini ${ }^{4}$

7 Scott McConnell ${ }^{5}$

8 Arturo Casadevall ${ }^{5}$

$10{ }^{1}$ North-Western Tuscany Blood Bank, Pisa University Hospital, Pisa, Italy.

$11{ }^{2}$ Department of Medicine and Surgery, University of Insubria, Varese, Italy.

12 fabrizio.maggi63@gmail.com

$13{ }^{3}$ Laboratory of Microbiology, ASST Sette Laghi, Varese, Italy.

$14{ }^{4}$ Division of Transfusion Medicine, Carlo Poma Hospital, 46100 Mantua, Italy;

15 massimo.franchini@asst-mantova.it

$16{ }^{5}$ Department of Medicine, Johns Hopkins School of Public Health and School of Medicine, Baltimore,

17 MD, USA; acasade1@jhu.edu; smcconn8@jhu.edu

19 "corresponding author: via Paradisa 2, 56124 Pisa, Italy. E-mail: daniele.focosi@gmail.com

21 Word count: abstract 108; body 4370.

22 Keywords: SARS-CoV-2; COVID-19; Spike; convalescent plasma; viral clearance.; Q493R; E484K;

23 deletions

24 Abbreviations: $\mathrm{nAb}$ : neutralizing antibodies; CCP : COVID19 convalescent plasma; PSM : propensity 25 score-matched; RCT : randomized controlled trials.

26 Author contributions: D.F. conceived the manuscript; F.M. analyzed the literature; S.M. provided the 27 figure and revised the final version; A.C. and M.F. revised the final version. All authors approved the 28 final version. 
medRxiv preprint doi: https://doi.org/10.1101/2021.11.11.21266207; this version posted November 11, 2021. The copyright holder for this preprint (which was not certified by peer review) is the author/funder, who has granted medRxiv a license to display the preprint in perpetuity. All rights reserved. No reuse allowed without permission.

\section{Abstract}

31 Accelerated SARS-CoV-2 evolution under selective pressure by massive deployment of neutralizing antibody-based therapeutics is a concern with potentially severe implications for public health. We review here reports of documented immune escape after treatment with monoclonal antibodies and COVID19 convalescent plasma (CCP). While the former is mainly associated with specific single amino acid mutations at residues within the receptor-binding domain (e.g., E484K/Q, Q493R, and S494P), the few cases of immune evasion after CCP were associated with recurrent deletions within the N-terminal domain of Spike protein (e.g, $\Delta$ HV69-70, $\Delta$ LGVY141-144 and $\Delta$ AL243-244). Continuous genomic monitoring of non-responders is needed to better understand immune escape

39 frequencies and fitness of emerging variants.

40

41 


\section{Introduction}

SARS-CoV-2 Spike protein is the target of neutralizing antibody ( $\mathrm{nAb}$ )-based therapeutics. Control of the COVID19 pandemic is being hampered by continued evolution of SARS-CoV-2, which includes mutations in the Spike protein that can affect immunogenicity and antibody-mediated neutralization. Evolutionary modeling suggests that SARS-CoV-2 strains harboring 1-2 deleterious mutations naturally exist, and their frequency increases steeply under positive selection by monoclonal antibodies (mAb) and vaccines [1]. In $2 \%$ of COVID cases, SARS-CoV-2 variants with multiple mutations occur, including in the Spike glycoprotein, which can become the dominant strains in as little as one month of persistent in-patient virus replication [2]. While mutations can occur as a natural phenomenon of SARS-CoV-2 RNA replication and editing, the pace of mutagen emergence can also be affected by small-chemical antivirals (e.g. remdesivir [3] or molnupiravir [4]). Since antibody-based therapies targeting the spike protein would also put selective pressure on SARS-CoV-2, it is reasonable to assume that widespread deployment of nAb-based therapeutics could accelerate Spike immune escape by selecting for variants resist neutralization.

Mutations that confer in vitro resistance to therapeutic anti-Spike mAbs have been characterized with various methods, and are informative about treatment-emergent immune escape. Deep mutational scanning (DMS) predicts protein expression, ACE2 binding, and mAb binding [5]. The method was first deployed with yeast display libraries [6], then evolved to phage display libraries (https://ibloomlab.github.io/SARS-CoV-2-RBD MAP clinical Abs/) [44] and finally mammalian cell surface display [7]. nAb binding is common within the fusion peptide and in the linker region before heptad repeat (HR) region 2. The complete escape maps forecast SARS-CoV-2 mutants emerging during treatment with $\mathrm{mAbs}$, and allow the design of escape-resistant nAb cocktails. Complete map of SARS-CoV-2 RBD mutations that escape bamlanivimab and its cocktail with etesevimab have been generated $[8,9]$.

Although DMS was also applied to polyclonal antibodies in COVID19 convalescent plasma (CCP) [10], the problem is much more complex such that it is almost impossible to identify escape mutations in CCP or vaccinee elicited sera, given the huge heterogeneity in antibody response among CCP donors and vaccinees, respectively. In vitro, continuous passaging of SARS-CoV-2 in the presence of a CCP unit with $n A b$ titer $>1: 10^{4}$ led to $\triangle F 140$ Spike mutation at day 45 , followed by E484K at day 73 , and an insertion in the N-terminal domain (NTD): these accumulating mutations led to complete immune escape [11]. Similarly, K417N, E484K, and N501Y mutations were selected when pseudotyped SARS$\mathrm{CoV}-2$ was cultured in the presence of vaccine-elicited mAbs [12]. Although some have speculated that the large-scale use of CCP for COVID-19 could have played a role in the emergence of variants there is no evidence for such an effect and the most likely explanation for regular emergence of variants has been huge number of affected individuals since each infection case provides a natural opportunity for variant creation [13].

In vivo, while intra-host SARS-CoV-2 mutation development is typically very low [14], faster mutation rates (referred as "accelerated evolution") have been found in longitudinal studies of immunodeficient patients who had persistent SARS-CoV-2 infections for several months and were treated with $n A b$-based therapeutics. In this study we analyze and compare the available mutational data from SARS-COV-2 under in vitro and in vivo selection and demonstrate that $\mathrm{mAb}$ and polyclonal (CCP) therapies elicit different types of mutational patterns.

\section{Methods}


87 We mined PubMed (which also indexes the bioRxiv and medrXiv preprint servers) for keywords 88 related to COVID19 ("COVID19", "SARS-CoV-2"), immune escape ("immune escape", "treatment89 emergent resistance") and nAb-based therapeutics ("convalescent plasma", "casirivimab", 90 "imdevimab", "bamlanivimab", etesevimab", "sotrovimab, "regdanvimab") both in vitro and in vivo.

91 Clinical cases were annotated for eventual underlying immune deficiency, concurrent treatments 92 and outcome. Figure 1 reports the study selection process according to PRISMA 2020 guidelines [15].

93 The 3D structural coordinates of the full Spike protein (PDBID 6VXX; residues 27-1252) [16] and the 94 receptor binding domain (PBDID 7BWJ; residues 319-529) [17], solved by cryo-electron microscopy 95 and X-ray crystallography, respectively, were used to map mutational positions of interest. Mapping 96 on the full Spike was used to illustrate the diverse set of mutations throughout the Spike glycoprotein, while the mutations localized to the RBD were illustrated using the more complete structural model obtained through crystallography. The mutations identified in each condition of in vivo or in vitro selection were tabulated and highlighted on the structures using color coding with 100 PyMOL [18].

\section{Results}

103

Our literature search revealed 32 papers that were then manually inspected to determine whether they included relevant information that was then retrieved, evaluated and organized into Tables.

Table 1 summarizes Spike protein mutations associated with in vitro resistance to mAbs targeting this protein. These mutations were used to filter clinical case reports of treatment resistance for evidence of immune escape (Table 2).

Table 3 summarizes Spike mutations found in clinical cases after CCP treatment, where, immune escape can be hypothesized to have occurred based on treatment failure, with the caveat that there is no definitive proof of immune escape due to heterogeneity of the (uncharacterized) polyclonal response.

112 Table 4 summarizes data from reports within-host clonal evolution within immunosuppressed patients not treated with nAb-based therapeutics.

114 Figure 2 depicts the Spike RBD mutations of concern for mAb binding detected in vitro and in vivo 115

and mutations detected after

usage. 
116 Table 1. Spike mutations associated with clinically-approved mAb resistance in vitro. Mutations conferring resistance to both $\mathrm{mAbs}$ within the cocktail are 117 underlined.

\begin{tabular}{|c|c|c|c|c|}
\hline manufacturer & $\begin{array}{c}\text { cocktail brand } \\
\text { name }\end{array}$ & active ingredient (brand name) & Spike mutations associated with in vitro resistance & ref \\
\hline \multirow{2}{*}{$\begin{array}{l}\text { Eli Lilly (AbCellera/ } \\
\text { Junshi) }\end{array}$} & \multirow[t]{2}{*}{ n.a. } & etesevimab (LyCoV016, CB6, JS016, LY3832479) & K417N/T, N460I, I472D, E484K, G485P, Q493R/K & \multirow[t]{2}{*}[8,9,19]{} \\
\hline & & bamlanivimab (LY-CoV555, LY3819253) & L452R, E484K, G485P, Q493R/K, S494P & \\
\hline \multirow[t]{2}{*}{ Regeneron/Roche } & \multirow{2}{*}{$\begin{array}{l}\text { REGN-COV2 } \\
\left.\text { (Ronapreve }{ }^{\circledast}\right)\end{array}$} & imdevimab (REGN10987) & E406W, K444x, G446x & \multirow[t]{2}{*}{ [8] } \\
\hline & & casirivimab (REGN10933) & E406W, F486x & \\
\hline Celltrion & - & regdanvimab (CT-P59) & n.a. & n.a. \\
\hline
\end{tabular}


Table 2. Case reports of immune escape after anti-Spike mAb treatment.

\begin{tabular}{|c|c|c|c|c|c|c|c|c|c|}
\hline mAb type & $\begin{array}{c}\text { age/se } \\
x \\
\text { (identif } \\
\text { ier) } \\
\end{array}$ & condition (treatments) & $\begin{array}{c}\text { day } \\
\text { mAb } \\
\text { admins } \\
\text { tered }\end{array}$ & $\begin{array}{l}\text { other antiviral } \\
\text { treatments }\end{array}$ & $\begin{array}{l}\text { SARS- } \\
\text { CoV-2 } \\
\text { strain }\end{array}$ & $\begin{array}{c}\text { Spike } \\
\text { mutations }\end{array}$ & $\begin{array}{c}\text { first } \\
\text { detected at } \\
\text { day }\end{array}$ & outcome & ref \\
\hline $\begin{array}{l}\text { REGN-CoV2 } \\
\text { cocktail }\end{array}$ & $45 / \mathrm{M}$ & $\begin{array}{l}\text { antiphospholipid } \\
\text { syndrome (steroids, } \\
\text { rituximab, ruxolitinib, } \\
\text { IVlg, } \\
\text { cyclophosphamide) }\end{array}$ & 45 & $\begin{array}{l}\text { remdesivir } \\
(5+10+5 \text { days })\end{array}$ & n.a. & $\begin{array}{l}\mathrm{E} 484 \mathrm{~K} / \mathrm{A} \text {, } \\
\mathrm{Y} 489 \mathrm{H} \text {, } \\
\mathrm{Q} 493 \mathrm{~K} \text { and } \\
\mathrm{N} 501 \mathrm{Y}\end{array}$ & 75 & death & $\begin{array}{l}\text { Choi et al [20] } \\
\text { Clarke et al } \\
{[21]}\end{array}$ \\
\hline \multirow[t]{6}{*}{$\begin{array}{l}\text { bamlanivimab } \\
\text { monotherapy } \\
\text { (700 mg iv) }\end{array}$} & $\begin{array}{l}\text { n.a./n. } \\
\text { a. } \\
\text { (B2_11 } \\
\text { ) }\end{array}$ & \multirow[t]{6}{*}{ immunocompetent } & \multirow[t]{6}{*}{$\begin{array}{l}\text { median } \\
4.5\end{array}$} & n.a. & n.a. & E484K & 3 after $m A b$ & n.a. & \multirow[t]{6}{*}{$\begin{array}{l}\text { Choudhary et al } \\
\text { [22] }\end{array}$} \\
\hline & $\begin{array}{l}\text { n.a./n. } \\
\text { a. } \\
\text { (B2_10 } \\
\text { ) }\end{array}$ & & & n.a. & n.a. & S494P & 6 after $m A b$ & n.a. & \\
\hline & $\begin{array}{l}\text { n.a./n. } \\
\text { a. } \\
\text { (B2_8) }\end{array}$ & & & n.a. & n.a. & E484K & 4 after $m A b$ & n.a. & \\
\hline & $\begin{array}{l}\text { n.a./n. } \\
\text { a. } \\
\text { (B2_7) }\end{array}$ & & & n.a. & n.a. & E484K & 6 after $m A b$ & n.a. & \\
\hline & $\begin{array}{l}\text { n.a./n. } \\
\text { a. } \\
\text { (B2_6) }\end{array}$ & & & n.a. & n.a. & $\begin{array}{l}\text { S494P } \\
+ \text { E484K } \\
\text { (frequency } \\
<20 \% \text { ) }\end{array}$ & 3 after $m A b$ & n.a. & \\
\hline & $\begin{array}{l}\text { n.a./n. } \\
\text { a. }\end{array}$ & & & n.a. & n.a. & E484Q & 4 after $m A b$ & n.a. & \\
\hline
\end{tabular}




\begin{tabular}{|c|c|c|c|c|c|c|c|c|c|}
\hline (B2__5) & & & & & & & & & \\
\hline $\begin{array}{l}\text { n.a./n. } \\
\text { a. } \\
\text { (B2_4) }\end{array}$ & & & n.a. & n.a. & E484K & 8 after $m A b$ & n.a. & & \\
\hline $\begin{array}{l}\text { n.a./n. } \\
\text { a. } \\
\text { (B2_3) }\end{array}$ & & & n.a. & n.a. & S494P & 6 after $m A b$ & n.a. & & \\
\hline $\begin{array}{l}\text { n.a./n. } \\
\text { a. } \\
\text { (B2_2) }\end{array}$ & & & n.a. & n.a. & E484Q & 3 after $\mathrm{mAb}$ & n.a. & & 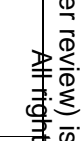 \\
\hline $72 / \mathrm{M}$ & $\begin{array}{l}\text { chronic lymphocyotic } \\
\text { leukemia and } \\
\text { hypogammaglobuline } \\
\text { mia (venetoclax and } \\
\text { rituximab } 17 \text { days } \\
\text { earlier); steroids } 21-26\end{array}$ & $\begin{array}{l}4 \quad(700 \\
m g)\end{array}$ & $\begin{array}{l}1 \text { BNT162 b2 dose } \\
20 \text { days before } \\
\text { CPP day } 10\end{array}$ & Alpha & $\begin{array}{l}\text { E484K and } \\
\text { Q493R }\end{array}$ & 6 & recovered at day 61 & $\begin{array}{l}\text { Truffot et } \\
\text { [23] }\end{array}$ & 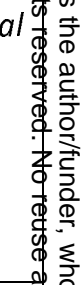 \\
\hline $55 / F$ & $\begin{array}{l}\text { acute myeloid } \\
\text { leukemia }\end{array}$ & 14 & $\begin{array}{l}\text { Remdesivir days } \\
23-27\end{array}$ & Alpha & $\begin{array}{l}\text { E484K and } \\
\text { Q493R, } \\
\text { S494P }\end{array}$ & 21 & negative at day 51 & Lohr et al [24] & 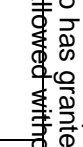 \\
\hline $70 / \mathrm{M}$ & $\begin{array}{l}\text { ANCA-associated } \\
\text { vasculitis with end- } \\
\text { stage renal disease } \\
\text { (rituximab and } \\
\text { prednisolone) }\end{array}$ & 2 & $\begin{array}{l}3 \text { units of CCP at } \\
\text { day } 16\end{array}$ & B.1 & $\begin{array}{l}\text { E484K } \\
\rightarrow E 484 Q, \\
\text { reverted to } \\
\text { E484K after } \\
\mathrm{CCP}\end{array}$ & 12 & died of MOF on day 20 & \multirow{3}{*}{\multicolumn{2}{|c|}{ 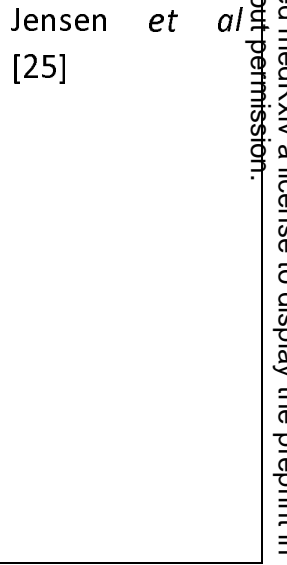 }} \\
\hline $40 / F$ & AIDS & 3 & $\begin{array}{l}\text { remdesivir and } 2 \\
\text { units of } C C P\end{array}$ & B..1. & E484K & 10 & recovered & & \\
\hline $60 / M$ & $\begin{array}{l}\text { relapsed follicular } \\
\text { lymphoma } \\
\text { (obinutuzumab, } \\
\text { thiotepa, cytarabine, } \\
\text { etoposide) }\end{array}$ & 76 & $\begin{array}{l}2 \text { CCP units on } \\
\text { day } 57 \text { and } 1 C C P \\
\text { unit on day } 59\end{array}$ & $\begin{array}{l}\text { B.1.17 } \\
7\end{array}$ & E484K & 87 & $\begin{array}{l}\text { recovered, negative at } \\
\text { day } 103\end{array}$ & & \\
\hline
\end{tabular}




\begin{tabular}{|c|c|c|c|c|c|c|c|c|}
\hline $65 / M$ & $\begin{array}{lr}\begin{array}{l}\text { heart } \\
\text { recipient (about } 30 \\
\text { years }\end{array} \\
\text { (cyclosporine, } \\
\text { azathioprine, } \\
\text { prednisolone) }\end{array}$ & 2 & none & $\begin{array}{l}\text { B.1.17 } \\
7\end{array}$ & E484K & 19 & $\begin{array}{l}\text { discharged at day } 40 \\
\text { after } 2 \text { negative NPS }\end{array}$ & \\
\hline $65 / M$ & $\begin{array}{l}\text { chronic lymphatic } \\
\text { leukemia }\end{array}$ & 45 & $\begin{array}{l}\text { remdesivir and } 3 \\
\text { units of CCP days } \\
52-62 \text {, } \\
\text { imdevimab/casiri } \\
\text { vimab about day } \\
70\end{array}$ & $\begin{array}{l}\text { B.1.25 } \\
8\end{array}$ & E484K & 52 & $\begin{array}{l}\text { recovered, negative at } \\
\text { day } 91\end{array}$ & \\
\hline $33 / \mathrm{M}$ & $\begin{array}{l}\text { Hodgkin lymphoma } \\
\text { (untreated) }\end{array}$ & 20 & dexamethasone & $\begin{array}{l}\text { B.1.36 } \\
2\end{array}$ & $\begin{array}{l}\Delta \mathrm{F} 140 \quad \rightarrow \\
\Delta \mathrm{PFLGVY139-} \\
144, \quad \mathrm{G} 485 \mathrm{R}, \\
\text { W258C }\end{array}$ & 45 & $\begin{array}{l}\text { hospitalized for HL } \\
\text { chemotherapy at end } \\
\text { of follow-up }\end{array}$ & \multirow[t]{2}{*}{$\begin{array}{l}\text { Bronstein et } a \\
\text { [26] }\end{array}$} \\
\hline $68 / \mathrm{M}$ & $\begin{array}{l}\text { chronic lymphocytic } \\
\text { leukemia (FCR in 2017, } \\
\text { prednisone for AlHA, } \\
\text { venetoclax + rituximab } \\
\text { in 2019) }\end{array}$ & 10 & $\begin{array}{l}\text { CPP days } 12 \text { and } \\
26 \text {, IVIg day } 21 \text {, } \\
\text { remdesivir days } \\
37-41\end{array}$ & Alpha & E484Q & 22 & discharged day 43 & \\
\hline n.a. & immunocompetent & 2 & n.a. & $\begin{array}{l}\text { B.1.31 } \\
1 \\
\end{array}$ & E484K & n.a. & resolved at home & Sabin et al [27] \\
\hline $87 / \mathrm{M}$ & immunocompetent & 2 & none & Alpha & $\begin{array}{l}\text { E484K } \\
+ \text { S494P }\end{array}$ & 6 & $\begin{array}{l}\text { discharged negative at } \\
\text { day } 27\end{array}$ & \multirow[t]{4}{*}{$\begin{array}{l}\text { Peiffer-Smadja } \\
\text { et al [28] }\end{array}$} \\
\hline $35 / \mathrm{M}$ & Immunocompetent & 2 & none & Alpha & $\mathrm{E} 484 \mathrm{~A} / \mathrm{K}$ & 6 & $\begin{array}{l}\text { discharged, negative at } \\
\text { day } 38\end{array}$ & \\
\hline $61 / \mathrm{M}$ & immunocompetent & 2 & steroids & Alpha & E484K & 12 & $\begin{array}{l}\text { negative at day } 8, \\
\text { hospitalized } \\
\text { unrelated reasons }\end{array}$ & \\
\hline $97 / M$ & immunocompetent & 4 & none & Alpha & E484K & 14 & died at day 35 because & \\
\hline
\end{tabular}




\begin{tabular}{|c|c|c|c|c|c|c|c|c|c|}
\hline & & & & & & & & of soft tissue infection & \\
\hline & $64 / M$ & $\begin{array}{l}\text { heart transplant } \\
\text { recipient }\end{array}$ & 2 & $\begin{array}{l}\text { corticosteroids } \\
\text { for } 10 \text { days }\end{array}$ & Alpha & Q493R & 26 & $\begin{array}{l}\text { discharged, negative at } \\
\text { day } 48\end{array}$ & \\
\hline \multirow{13}{*}{$\begin{array}{l}\text { bamlanivimab } \\
700 \mathrm{mg}+ \\
\text { etesevimab } \\
1400 \quad \mathrm{mg} \\
\text { cocktail }\end{array}$} & n.a. & n.a. & 2 & n.a. & n.a. & S494P & 11 & $\begin{array}{l}\text { recovered, not } \\
\text { detected in samples at } \\
\text { day }\end{array}$ & $\begin{array}{l}\text { Gottlieb et al } \\
\text { [29] }\end{array}$ \\
\hline & $73 / \mathrm{M}$ & $\begin{array}{l}\text { cholangiocarcinoma } \\
\text { (steroids) }\end{array}$ & 2 & none & Alpha & Q493R & 7 & died day 18 & $\begin{array}{l}\text { Focosi et al } \\
{[30]}\end{array}$ \\
\hline & $63 / \mathrm{M}$ & $\begin{array}{l}\text { allogeneic } \text { HSCT } \\
\text { recipient for mycosis } \\
\text { fungoides }\end{array}$ & n.a. & none & Alpha & Q493R & 15 & discharged at day 2 & 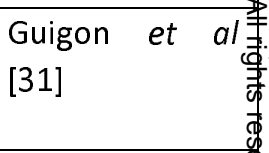 \\
\hline & n.a. & $\begin{array}{ll}\text { solid } & \text { organ } \\
\text { transplantation } & \end{array}$ & n.a. & none & Alpha & Q493R & 7 & n.a & \multirow{5}{*}{ 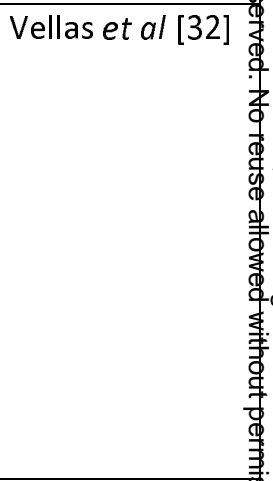 } \\
\hline & n.a. & $\begin{array}{ll}\text { solid } & \text { organ } \\
\text { transplantation } & \end{array}$ & n.a. & none & Alpha & Q493R & 7 & n.a. & \\
\hline & n.a. & $\begin{array}{l}\text { solid organ } \\
\text { transplantation }\end{array}$ & n.a. & none & Alpha & Q493R & 14 & n.a. & \\
\hline & n.a. & $\begin{array}{ll}\text { solid } & \text { organ } \\
\text { transplantation } & \end{array}$ & n.a. & none & Alpha & Q493K & 7 & n.a. & \\
\hline & n.a. & $\begin{array}{ll}\text { solid } & \text { organ } \\
\text { transplantation } & \end{array}$ & n.a. & none & Alpha & E484K & 21 & n.a. & \\
\hline & $34 / F$ & B-ALL & \multirow[t]{5}{*}{$<5$ days } & $\begin{array}{l}2 \text { CCP units days } \\
29-30\end{array}$ & Alpha & Q493R & n.a. & \multirow[t]{5}{*}{$\begin{array}{l}\text { all were rescued with } \\
\text { CCP }\end{array}$} & \multirow[t]{5}{*}{$\begin{array}{l}\text { Pommeret et al } \frac{\mathrm{c}}{\mathrm{C}} \\
\text { [33] }\end{array}$} \\
\hline & $62 / F$ & Hodgkin lymphoma & & $1 \mathrm{CCP}$ unit day 26 & Alpha & Q493R & n.a. & & \\
\hline & $63 / F$ & follicular lymphoma & & $\begin{array}{l}2 \text { CCP units days } \\
30-31\end{array}$ & Alpha & Q493R & n.a. & & \\
\hline & $67 / F$ & follicular lymphoma & & $\begin{array}{l}2 \text { CCP units days } \\
15-16\end{array}$ & Alpha & n.a. & n.a. & & \\
\hline & $57 / \mathrm{M}$ & $\begin{array}{ll}\text { chronic lymphocytic } \\
\text { leukemia }\end{array}$ & & $\begin{array}{l}2 \text { CCP units days } \\
30-31\end{array}$ & Alpha & E484D & n.a. & & \\
\hline
\end{tabular}




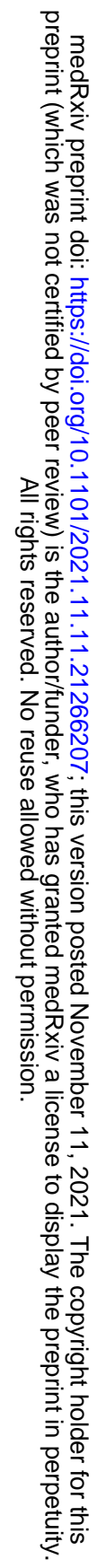


Table 3. Case reports of immune escape after CCP treatment.

\begin{tabular}{|c|c|c|c|c|c|c|c|c|c|}
\hline $\begin{array}{l}\text { age/sex } \\
\text { (identifier) }\end{array}$ & condition & $\begin{array}{l}\text { CCP } \\
\text { schedule } \\
\text { (and } \\
\text { titer) }\end{array}$ & co-treatments & $\begin{array}{l}\text { SARS- } \\
\text { CoV-2 } \\
\text { strain }\end{array}$ & Spike mutations & $\begin{array}{c}\text { first } \\
\text { detected } \\
\text { at day }\end{array}$ & outcome & ref & 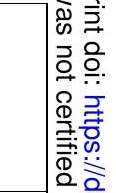 \\
\hline \multirow[t]{2}{*}{$71 / \mathrm{F}$} & \multirow{2}{*}{$\begin{array}{c}\text { chronic lymphocytic } \\
\text { leukemia and iatrogenic } \\
\text { hypogammaglobulinemia }\end{array}$} & \multirow{2}{*}{$\begin{array}{c}70(1: 60) \\
\text { and } 81 \\
(1: 160)\end{array}$} & \multirow[t]{2}{*}{ IVIG q4-6w } & \multirow[t]{2}{*}{ n.a. } & $\Delta$ PFLGVYY139-145 & 49 & \multirow{2}{*}{$\begin{array}{l}\text { negative } \\
\text { NPS since } \\
\text { day } 105\end{array}$} & \multirow[t]{2}{*}{ Avanzato et al [34] } & \\
\hline & & & & & $\Delta$ LGVY141-144 & $\begin{array}{l}70 \text { (poor } \\
\text { causality) }\end{array}$ & & & \\
\hline \multirow[t]{3}{*}{$73 / \mathrm{M}$} & \multirow[t]{3}{*}{ CAR-T-cell recipient } & \multirow{3}{*}{$\begin{array}{l}\text { low titre } \\
\text { days } 2 \\
\text { and } 58\end{array}$} & \multirow{3}{*}{$\begin{array}{c}\text { remdesivir days } 5- \\
10,63-74 \\
\text { dexamethasone days }\end{array}$} & \multirow[t]{3}{*}{$\mathrm{GH}$} & R190K and G1124D & 13 & \multirow{3}{*}{$\begin{array}{c}\text { died day } \\
74\end{array}$} & \multirow[t]{3}{*}{ Hensley et al [35] } & \\
\hline & & & & & $\begin{array}{c}\Delta \mathrm{Y} 144, \mathrm{D} 215 \mathrm{G} \text {, and } \\
\mathrm{N} 501 \mathrm{~T}\end{array}$ & 67 & & & \\
\hline & & & & & $\Delta \mathrm{H} 146$ & 72 & & & \\
\hline $70 / \mathrm{M}$ & $\begin{array}{c}\text { B-cell depletion and } \\
\text { hypogammaglobulinemia }\end{array}$ & $\begin{array}{c}63,65 \\
102\end{array}$ & $\begin{array}{l}\text { remdesivir day } 38- \\
48,52-62 \text { and } 91- \\
101\end{array}$ & n.a. & $\mathrm{D} 796 \mathrm{H}$ and $\Delta \mathrm{HV} 69-70$ & 57 & $\begin{array}{l}\text { died on } \\
\text { day } 102\end{array}$ & Kemp et al [36] & 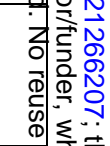 \\
\hline $21 / \mathrm{M}$ & $\begin{array}{c}\text { B-acute lymphoblastic } \\
\text { leukemia (CART } \\
\text { tisagenlecleucel) }\end{array}$ & $\begin{array}{c}78,103, \\
110,123, \\
130,137 \\
144,158 \\
165,172\end{array}$ & $\begin{array}{l}\text { remdesivir (2 5-days } \\
\text { courses) }\end{array}$ & n.a. & $\begin{array}{c}3 \text { major allele variants } \\
\text { emerged between } \\
\text { days } 0 \text { and } 40 \text { with an } \\
\text { additional } 4 \text { major and } \\
7 \text { minor allele variants } \\
\text { by day } 144 \text { ( } \Delta \text { LGV141- } \\
143, \Delta Y 145, \\
\Delta L G V Y 141-144, \\
\Delta N L 211-212, N 440 K, \\
\text { V483A, and E484Q) }\end{array}$ & 144 & $\begin{array}{l}\text { positive } \\
\text { NPS at end } \\
\text { of follow- } \\
\text { up (day } \\
250 \text { ) }\end{array}$ & Truong et al [37] & 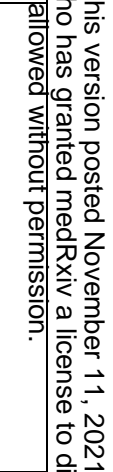 \\
\hline $50 / \mathrm{M}$ & $\begin{array}{l}\text { kidney transplant recipient } \\
\text { (tacrolimus, steroids) }\end{array}$ & 1 & tocilizumab day 2 & B.1.369 & $\begin{array}{c}\text { Q493R, } \Delta \text { AL243-244 } \\
\text { had } \sim 70 \% \text { frequency; } \\
\Delta \mathrm{LGVY141-144,} \mathrm{E484K} \\
\text { and Q493K had } \sim 30 \% \text {, } \\
\sim 20 \% \text { and } \sim 10 \%\end{array}$ & 21 & $\begin{array}{l}\text { died on } \\
\text { day } 94\end{array}$ & Chen et al [38] & \\
\hline
\end{tabular}




\begin{tabular}{|c|c|c|c|c|c|c|c|c|c|}
\hline & & & & & frequency & & & & ) \\
\hline $75 / M$ & B-CLL (FCR, ibrutinib) & $\begin{array}{l}2 \text { units on } \\
\text { day } 70,2 \\
\text { units on } \\
\text { days } 127- \\
\quad 128\end{array}$ & $\begin{array}{l}\text { remdesivir days 24- } \\
33 \text { and } 60-64\end{array}$ & n.a. & $\begin{array}{c}\mathrm{H} 49 \mathrm{Y}, \Delta \mathrm{Y} 144, \\
\Delta \mathrm{LLA} 241-243, \\
\Delta \mathrm{AL} 243-244, \mathrm{~L} 242 \mathrm{H}, \\
\mathrm{A} 243 \mathrm{P}, \mathrm{F} 490 \mathrm{~S}, \\
\mathrm{~N} 1178 \mathrm{~N}, \text { and } \mathrm{C} 1250 \mathrm{~F}\end{array}$ & 80 & $\begin{array}{l}\text { still } \\
\text { positive at } \\
\text { end of } \\
\text { follow-up } \\
\text { (day 333) }\end{array}$ & Monrad et al [39] & 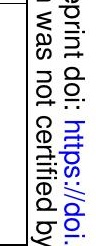 \\
\hline $60 / \mathrm{M}$ & $\begin{array}{l}\text { mantle-cell lymphoma and } \\
\text { associated B-cell } \\
\text { immunodeficiency } \\
\text { (rituximab, bispecific mAb, } \\
\text { cyclophosphamide, } \\
\text { doxorubicin, prednisone) }\end{array}$ & 31,122 & $\begin{array}{c}\text { remdesivir day } 30 \\
\text { and } 122\end{array}$ & n.a. & $\begin{array}{l}\text { mutations in ORF1a } \\
\text { but not in Spike }\end{array}$ & n.a. & $\begin{array}{l}\text { still } \\
\text { positive at } \\
\text { end of } \\
\text { follow-up } \\
\text { (day 156) }\end{array}$ & Baang et al [40] & 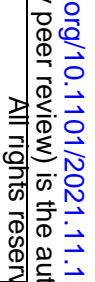 \\
\hline $40 / F$ & $\begin{array}{c}\text { diffuse large B-cell } \\
\text { lymphoma (CART) and } \\
\text { hypogammaglobulinemia }\end{array}$ & $\begin{array}{l}\text { high-titer } \\
\text { day 2, } \\
313\end{array}$ & $\begin{array}{l}\text { IVIG, remdesivir day } \\
2 \text { and } 313\end{array}$ & B.1.332 & $\begin{array}{c}\Delta \mathrm{LHR} 244-246 \text { and } \\
\mathrm{A} 243 \mathrm{G}\end{array}$ & $\begin{array}{l}313 \text { (poor } \\
\text { causation) }\end{array}$ & $\begin{array}{c}\text { discharged } \\
\text { day } 324, \\
\text { cleared at } \\
\text { day } 335\end{array}$ & Nussenblatt et al [41] & 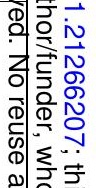 \\
\hline $70 / F(A)$ & $\begin{array}{l}\text { follicular lymphoma } \\
\text { (obinutuzumab-CHOP) }\end{array}$ & $\begin{array}{c}23,34, \\
49,55 \\
56,62 \\
65,70 \\
73,77 \\
84,86 \\
90,94 \\
106\end{array}$ & steroids & B.1.1.29 & L18F, R682Q, $\Delta \mathrm{Y} 144$ & 50 & $\begin{array}{l}\text { died } 5 \\
\text { months } \\
\text { later }\end{array}$ & Khatamzas et al [42] & 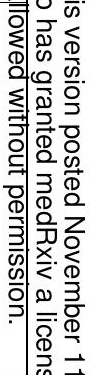 \\
\hline $70 / \mathrm{M}$ & $\begin{array}{l}\text { mantle cell lymphoma (R- } \\
\text { BAC) }\end{array}$ & 88 & $\begin{array}{l}\text { darunavir/ritonavir, } \\
\text { hydroxychloroquine, } \\
\text { methylprednisolone, } \\
\text { tocilizumab days } 1 \\
78, \text { rem desivir days } \\
45-50 \text { and } 78-87, \\
180-184 \text { and } 210-\end{array}$ & B.1.1 & $\begin{array}{c}\mathrm{H} 69 \mathrm{Y} / \mathrm{P}, \mathrm{V} 70 \mathrm{G} \text { and } \\
\text { S982A }\end{array}$ & 238 & $\begin{array}{l}\text { died on } \\
\text { day } 271 \text {, } \\
\text { still } \\
\text { positive at } \\
\text { day } 268\end{array}$ & Sepulcri et al [43] & 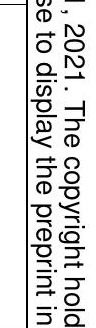 \\
\hline
\end{tabular}




\begin{tabular}{|c|c|c|c|c|c|c|c|c|}
\hline & & & 214, IVIg & & & & & \\
\hline $40 / M$ & $\begin{array}{c}\text { autologous hematopoietic } \\
\text { stem cell transplant due to } \\
\text { a DLBCL }\end{array}$ & $\begin{array}{l}2 \text { doses } \\
\text { on days? }\end{array}$ & IVIg & B.1.128 & $\begin{array}{c}\Delta \text { LGV141-143 } \rightarrow \\
\Delta \text { LGVY141-144 }\end{array}$ & 134 & $\begin{array}{l}\text { negative } \\
\text { PCR on } \\
\text { day } 196\end{array}$ & $\begin{array}{l}\text { Mendes-Correa et al } \\
{[44]}\end{array}$ \\
\hline
\end{tabular}


123 Table 4. Intrahost variation in Spike sequence detected in immunocompromised patients not receiving nAb-based treatments.

\begin{tabular}{|c|c|c|c|c|c|c|c|}
\hline $\begin{array}{l}\text { age/sex } \\
\text { (identifier) }\end{array}$ & condition & $\begin{array}{l}\text { antiviral } \\
\text { treatments }\end{array}$ & $\begin{array}{l}\text { SARS- } \\
\text { CoV-2 } \\
\text { strain }\end{array}$ & Spike mutations & $\begin{array}{c}\text { first } \\
\text { detected } \\
\text { at day }\end{array}$ & outcome & ref \\
\hline $47 / F$ & $\begin{array}{c}\text { diffuse large B cell } \\
\text { lymphoma (rituximab plus } \\
\text { polychemotherapy) }\end{array}$ & n.a. & B.1.1.163 & $\begin{array}{l}\text { Y453F, } \Delta \text { HV69-70, } \\
\text { S50L, } \Delta \text { LGVY141-144, } \\
\text { T470N, and D737G }\end{array}$ & 120 & negative PCR on day 132 & $\begin{array}{l}\text { Bazykin et } \\
\text { al [45] }\end{array}$ \\
\hline $61 / F$ & $\begin{array}{l}\text { diffuse large B cell } \\
\text { lymphoma stage IVB }\end{array}$ & $\begin{array}{l}\text { remdesivir for } 10 \\
\text { days, high-dose } \\
\text { steroids for } 7 \\
\text { days }\end{array}$ & B.1.1.401 & $\begin{array}{c}\text { V3G, S50L, N87S, } \\
\text { A222V, } \\
\text { DLTTRTQLPPAYTN18- } \\
30 \text { and } \Delta \text { LGVY141-144 }\end{array}$ & 164 & negative PCR at day 197 & $\begin{array}{l}\text { Borges et } \\
\text { al [46] }\end{array}$ \\
\hline $3 / F(1)$ & $\begin{array}{l}\text { B-cell acute lymphoblastic } \\
\text { leukemia (chemotherapy) }\end{array}$ & n.a. & $20 \mathrm{C}$ & $\begin{array}{c}\text { silent } 1410 \mathrm{I} \\
(22792: \mathrm{C} / \mathrm{A})\end{array}$ & 27 & negative PCR at day 91 & \multirow[t]{3}{*}{$\begin{array}{l}\text { Truong et } \\
a /[37]\end{array}$} \\
\hline \multirow[t]{2}{*}{ 2/M (3) } & \multirow{2}{*}{$\begin{array}{l}\text { B-cell acute lymphoblastic } \\
\text { leukemia }\end{array}$} & \multirow{2}{*}{$\begin{array}{c}\text { remdesivir for } 5 \\
\text { days }\end{array}$} & \multirow[t]{2}{*}{$20 \mathrm{C}$} & V483A and E484Q & 139 & \multirow[t]{2}{*}{ negative PCR at day 196} & \\
\hline & & & & 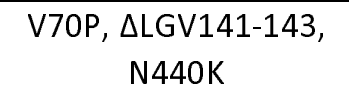 & 162 & & \\
\hline \multirow[t]{4}{*}{$37 / F$} & \multirow{4}{*}{$\begin{array}{c}\text { advanced HIV and } \\
\text { antiretroviral treatment } \\
\text { failure }\end{array}$} & \multirow[t]{4}{*}{ dexamethasone } & \multirow[t]{4}{*}{ B.1.1.273 } & $\mathrm{E} 484 \mathrm{~K}$ & 6 & \multirow[t]{4}{*}{ negative at day 233} & \multirow{4}{*}{$\begin{array}{l}\text { Karim et al } \\
\text { [47] }\end{array}$} \\
\hline & & & & K417T and F490S & 71 & & \\
\hline & & & & L455F and F456L & 106 & & \\
\hline & & & & D427Y and N501Y & 190 & & \\
\hline \multirow[t]{2}{*}{$80 / \mathrm{M}$} & \multirow{2}{*}{$\begin{array}{c}\text { chronic lymphocytic } \\
\text { leukemia and } \\
\text { hypogammaglobulinemic }\end{array}$} & \multirow{2}{*}{$\begin{array}{l}\text { remdesivir days } \\
213-230, \text { REGN- } \\
\text { COV-2 day } 265\end{array}$} & \multirow[t]{2}{*}{ B.52 } & L179 & 58 & \multirow[t]{2}{*}{ negative PCR day 311} & \multirow{2}{*}{$\begin{array}{l}\text { Kavanagh } \\
\text { Williamson } \\
\text { et al [48] }\end{array}$} \\
\hline & & & & $\begin{array}{c}\text { S255F, S477N, H655Y, } \\
\text { D1620A, } \Delta \text { HV69-70 }\end{array}$ & 155 & & \\
\hline $40 / \mathrm{M}$ & $\begin{array}{c}\text { autologous hematopoietic } \\
\text { stem cell transplant due to } \\
\text { a DLBCL }\end{array}$ & IVIg & B.1.128 & $\begin{array}{c}\Delta \text { LGV141-143 } \rightarrow \\
\text { LLGVY141-144 }\end{array}$ & & negative PCR on day 196 & $\begin{array}{l}\text { Mendes- } \\
\text { Correa et } \\
a l[44]\end{array}$ \\
\hline n.a./n.a. & transplant recipient & remdesivir & n.a. & $\begin{array}{c}\text { S13I, T95I, E484G, } \\
\text { F490L, } \Delta \text { LGVY141-144, } \\
\Delta \text { LHRS244-247, and } \\
\Delta \text { SPRRARSV680-687 }\end{array}$ & n.a. & n.a. & $\begin{array}{l}\text { Weigang et } \\
\text { al [49] }\end{array}$ \\
\hline
\end{tabular}




\begin{tabular}{|c|c|c|c|c|c|c|c|}
\hline n.a./n.a. & $\begin{array}{c}18 \text { B-cell non-Hodgkin } \\
\text { lymphoma }\end{array}$ & $\begin{array}{c}44 \% \text { CCP } \\
37 \% \text { remdesivir }\end{array}$ & n.a. & n.a. & requested & n.a. & $\begin{array}{ll}\text { Lee et al } \\
{[50]}\end{array}$ \\
\hline
\end{tabular}

(2)


125 Figure legends.

126 Figure 1. PRISMA flow diagram of study selection.

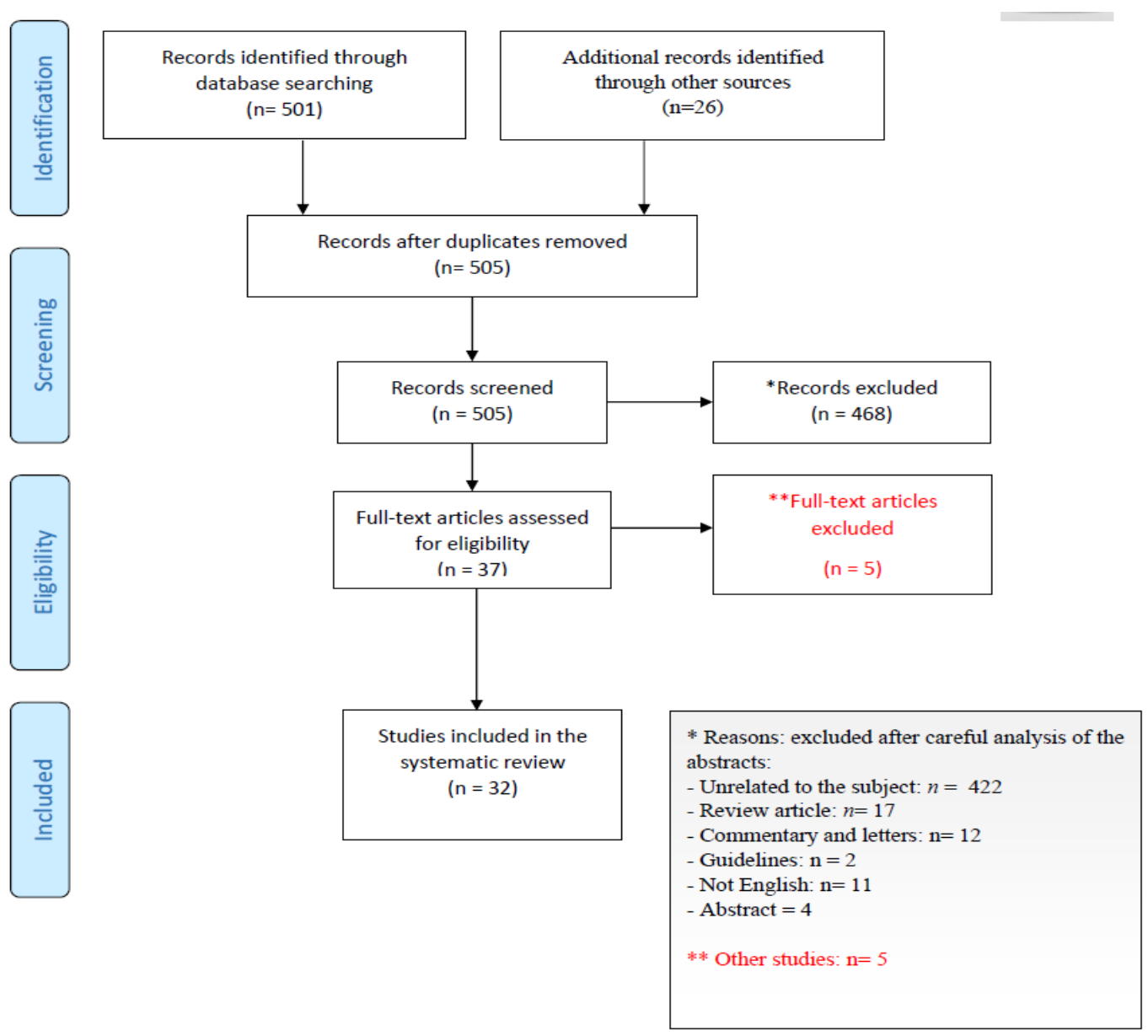


Top panel) The full SARS-CoV-2 S (spike) glycoprotein homotrimer (PDBID 6VXX) [16] in the prefusion conformation is shown in surface representation, with each spike monomer colored a different shade of green. $\mathrm{N}$-linked glycosylations which were resolved in the cryo-EM map in this structure $(16 / 22$ sequons per protomer) are displayed as magenta sticks. The receptor binding domains (RBDs), in the closed state, are highlighted in 3 shades of blue corresponding to the shade of the corresponding trimer. Escape mutations from case reports of patients treated with CCP are highlighted in orange. Spike mutations associated with immune escape from clinically approved $\mathrm{mAb}$ treatments in vitro or from case reports are highlighted in red, while escape mutations identified in both patients who received with clinically approved $\mathrm{mAb}$ treatments and CCP treatment are colored yellow. The full spike is shown oriented along the long axis (left) and rotated 90 degrees to display mutations concentrated in the RBDs. Note that mutations located on unresolved loops on the cryo-EM map of the full spike are not visualized (L18, V70, Y144, Y145, D146, R246, W258, G446, N460, 1472, V483, E484, G485, F486, R682, N1178 and C1250).

Bottom panel) A table summarizing escape mutations localized to the RBD resulting from $\mathrm{mAb}$ treatments in vitro and case reports, as well as from CCP treatment. The crystal structure of single RBD domain (PBDID: 7BWJ)[17] from a more complete model (no missing loops) is displayed in surface view with the secondary structure superimposed in cartoon representation. Each escape mutation residue is highlighted by coloration according to the legend to right, and sidechains shown as sticks. In cases where a certain position corresponds to escape mutations from multiple treatments, the position is colored white and the label includes asterisks with the colors corresponding to each treatment where the escape mutation was identified. All figures were generated in PyMOL [18]. 

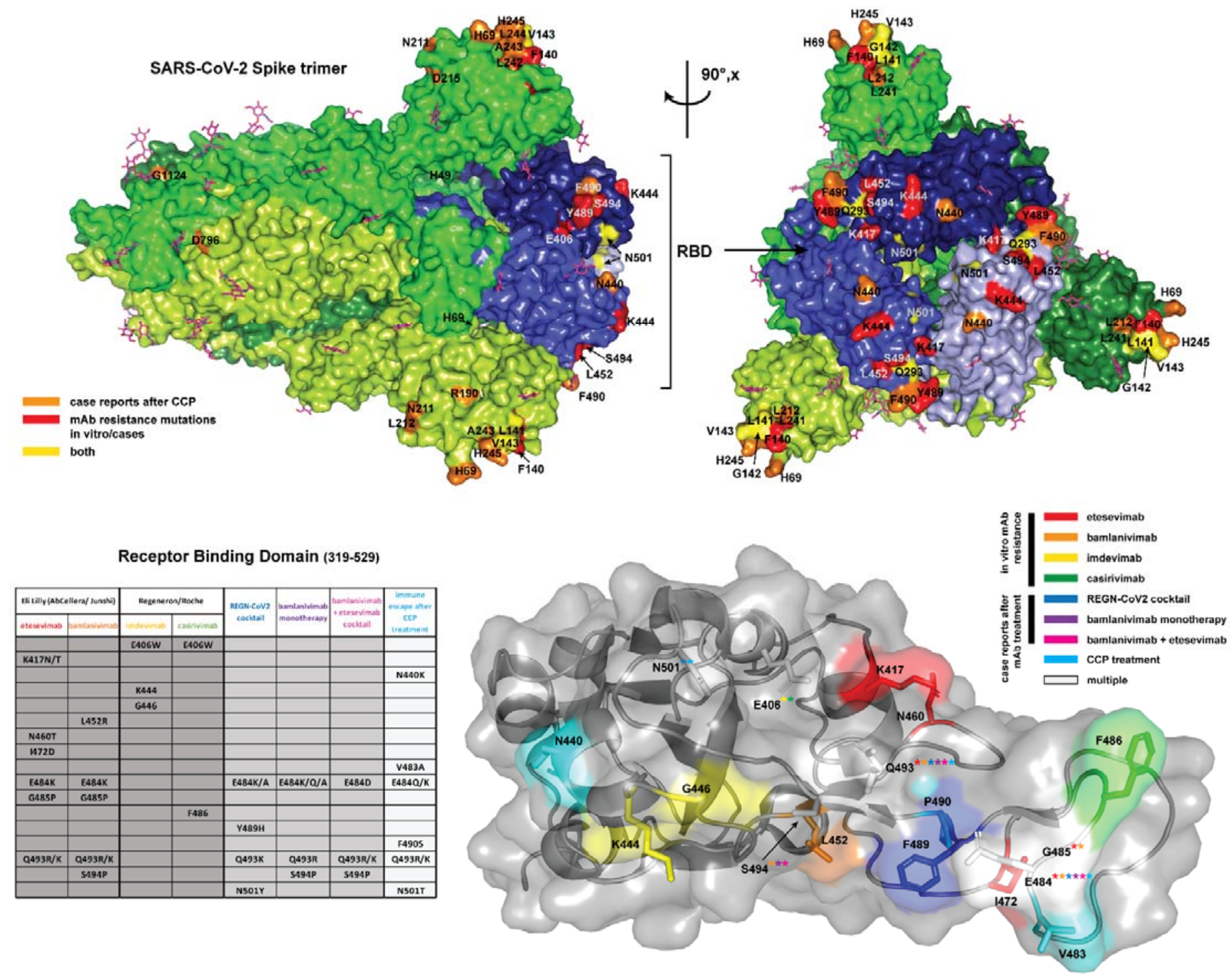
146

147

148

149

150

151

152

153

154

155

156

157

158

159

160

161

162

163

164

165

166

167

168

169

170

171

172

173

174

175

176

177

178

179

180

181

182

183

184

185

186

187

188

189

190

\section{Discussion}

Escape from nAb based therapeutics provides a crucial demonstration that these immune therapies target protective antigens, which the pathogen actively evades. Hence, the emergence of neutralizing-resistant variants in individuals receiving $\mathrm{mAb}$ and $\mathrm{CCP}$ provides powerful evidence for their antiviral activity. This evidence is independent of reduction in viral load, which has been reported with $\mathrm{mAbs}$ given early in disease but have been an inconsistent finding in randomized controlled trials (RCT) of CCP for COVID-19 [51].

Getting frequencies for this phenomenon from case series is not possible due to the high risk of selection biases, which would yield unrealistically high frequencies. In contrast, RCTs with their control groups are the suggested reference. With bamlanivimab, there was no emergence of resistance in the patients receiving $7000 \mathrm{mg}$, but resistance was reported in patients receiving 700 mg ( 8 cases: $7 \%$ vs $0 \%$ with placebo) [22]. Putative treatment-emergent bamlanivimab-resistant variants were detected in $7.1 \%$ of patients $(7 / 98)$ in the $700 \mathrm{mg}$ group, $9.8 \%$ of patients $(10 / 102)$ in the $2800 \mathrm{mg}$ group, $11.3 \%$ of patients $(11 / 97)$ in the $7000 \mathrm{mg}$ group, $1 \%$ of patients $(1 / 102)$ in the bamlanivimab and etesevimab combination group, and in $4.8 \%$ of patients $(7 / 145)$ in the placebo group. The bamlanivimab monotherapy groups had a higher frequency of patients in whom a variant was detected at more than 1 time point during the viral time course $(4.1 \%$ for the $700 \mathrm{mg}$ group, $5.9 \%$ for the $2800 \mathrm{mg}$ group, and $7.2 \%$ for the $7000 \mathrm{mg}$ group) than the placebo group or the bamlanivimab and etesevimab combination group (both 0\%) [29]. Apart from registration trials, the largest case series to date evaluated the impact of mAbs on the nasopharyngeal (NP) viral load and virus quasi-species of mAb-treated patients using single-molecule real-time sequencing after bamlanivimab alone (4 patients), bamlanivimab/etesevimab (23 patients) and casirivimab/Imdevimab (5 patients) [32]. To date a single case of immune escape has been reported for the non-overlapping REGN-COV2 cocktail, and accordingly hamster models and clinical trials showed no emergence of variants [52]. Since mAb therapy by definition targets only a single epitope within the RBD, it is unsurprising that escape mutations observed after in vitro and in vivo selection by these $m A$ bs were single amino acid substitutions localized almost exclusively to the RBD (Figure 2, bottom panel; Tables 1 and 2), as expected from in vitro studies with single mAb, but largely prevented by non-overlapping mAb cocktails [53].

In contrast to mAb therapeutics, immune escape under CCP has not been investigated in RCTs. Hence evidences exclusively stem from case series and case reports [54], and is further complicated by exposure to multiple CCP units from different donors, each one having a polyclonal response at differing titers and affinity. Unfortunately $n A b$ titers were very rarely determined or reported, precluding correlations between emergence of resistance and subneutralizing CCP doses. Overall, it seems that escape variants from CCP selection have not been reported as commonly nor emerged as fast. E.g., none out of 8 recipients of HSCT or CART who were treated with CCP and tested SARS-CoV2-positive for 2 months showed significant mutations compared to the original strain [55]. Review of the Spike protein changes associated with resistance after CCP therapy reveal that most of them had in-frame amino acid deletions in a flexible region that is partially solvent exposed and forms a $\beta$ strand: plasticity may contribute to the structural permissibility of the identified deletions. The NTD is a flexible region that can be affected by immune escape via either insertions (causing additional glycosylation sites [11]) or recurrently deleted regions (RDR) $\triangle H V 69-70$ (RDR1), $L$ LGVY141-144 and $\triangle \mathrm{D} 146$ (RDR2), $\Delta \mathrm{I} 210$ (RDR3) and $\triangle \mathrm{AL243}-244$ (RDR4) [56] : RDR1, RDR2 and RDR4 correspond to NTD loops N2, N3 and N5, whereas RDR3 falls between N4 and N5. 
191

192

193

194

195

196

197

198

199

200

201

202

203

204

205

206

207

208

209

210

211

212

213

214

215

216

217

218

219

220

221

222

223

224

225

226

227

228

229

230

231

232

233

234

235

236

237

Deletions of amino acids from a protein structure generally results in greater structural changes than single amino acid changes, since these reduce the size of the protein and can trigger changes that propagate through the whole structure. Furthermore, the mechanism for the emergence of deletion variants appears to be very different from the single amino acid changes that are frequent from error-prone RNA replication and could involve deletions from RNA editing. Since CCP targets a large number of epitopes in the Spike protein while mAbs target a single epitope these molecular differences parallel what is expected from their respective selection pressures in the sense that escape from polyclonal preparations requires larger antigenic structural changes than escape from mAbs. In contrast to escape mutations selected for by mAb therapy, CCP selection yields point mutations throughout the Spike protein. This reflects the vast antigenic surface area covered by the polyclonal antibodies within CCP. Escape mutations would be theoretically selected for on the basis of the most potent antibodies present in a particular CCP unit, which may vary markedly from donor to donor, which could explain the generally divergent evolution of SARS-CoV-2 in the presence of CCP. However, residues 141-144 and 243-244 are the sites of mutations or deletions in several cases, indicating these sites may offer effective escape from CCP derived from many donors, possibly by triggering a large-scale conformational rearrangement, as discussed above. As RBD binding antibodies are often neutralizing via ACE2 receptor occlusion, it is interesting that only $23 \%$ of CCP case studies identified escape mutations with in the RBD (Figure 2, top panel; Table 3). This suggests that antibody binding to other sites on the Spike protein may have additional mechanisms of neutralization (i.e., by preventing conformational change after ACE2 engagement), or that additional antibody mediated immune responses (e.g., $A D C C$ ) are equally important as direct neutralization to the antiviral response to SARS-CoV-2.

Nothing can be inferred about the fitness of an emerging mutant in the absence of selective pressure, but it is of interest that one variant with the E484K mutant that emerged after bamlanivimab therapy was able to infect multiple household contacts [27]. In vitro, several mutants showed similar infectivity to wild type strain but resistance to different CCP donors [36]. In one instance of immune escape associated with CCP, a variant with D796H mutation manifested modestly reduced sensitivity to neutralization by CCP that was associated with reduced infectivity, which was only partly compensated by $\Delta H V 69-70$ [36]. Even if immune escape in registration trials has been a rare phenomenon, it should be considered that in the real-world practice mAbs targeting the SARS-CoV-2 Spike protein are being reserved for use in high-risk (immunocompromised) patients. Considering the huge size of a pandemic, the likelihood of immune escape becomes relevant, raising the possibility that rare variants with enhanced fitness could drive next pandemic waves. Notably, several mutations have recurred in VOC and VOIs (e.g. E484K found in Beta and Gamma, E484Q found in Delta, or $\Delta$ LHR244-246 [41] found in VOI lambda), raising the possibility that such variants emerged during treatment of patients (iatrogenic variants), but such inference will likely remain very hard to prove. E406W mutation has never been reported in GISAID, and other E406 mutations remain exceedingly rare (worldwide 318 cases of E406Q, 41 cases of E406D, and 2 cases each from USA for E406G, E406A, E406K, and 1 case of E406V out of 4,410,787 sequences deposited in GISAID as of October 25, 2021). Similarly, Q493R has only been reported in 244 sequences and Q493K in 138 sequences (source: Outbreak.info). Lack of fixation of those mutation facilitates the imputation that these require $\mathrm{mAb}$ selective pressure and/or effective infection control techniques in the care of those patients prevented spill over to the general population.

Within host variation (so-called "quasi-species swarm") is a natural phenomenon which has been reported for SARS-CoV-2 in immunocompetent patients and ultimately facilitates persistence of infection. Among 33 patients having positive NPS PCR for an average of 18 days, Voloch et al observed a distinguishing pattern of mutations over the course of the infection mainly driven by 
increasing $A \rightarrow U$ and decreasing $G \rightarrow A$ signatures, including Spike mutations (V362L, T553I, H655Y, A688V, S691F, S884F, V1176F). G $\rightarrow$ A mutations are driven by RNA-editing enzyme activities typical of innate immunity [57]. Nevertheless, several covariates can facilitate immune escape.

Immunosuppression has been postulated to be an accelerator for viral evolution. Actually, Table 4 shows that very few case reports have detailed intraclonal (within-host) evolution in patients receiving immunosuppressive treatment, and, in the absence of nAb-based therapeutics, Spike mutations rarely occurred [55].

On the other hand, co-administered small chemical antivirals can be mutagenic per se. Remdesivir can adopt both amino and imino tautomeric conformations to base-pair with RNA bases [58]. Both amino-remdesivir: $G$ and imino-remdesivir: $C$ pairs could be quite mutagenic. Serial in vitro passages of SARS-CoV-2Engl2 in cell culture media supplemented with remdesivir selected for drug-resistant viral populations. Remdesivir triggers the selection of SARS-CoV-2 variant with a E802D mutation in the RdRp sufficient to confer decreased sensitivity to remdesivir without affecting viral fitness. The analysis of more than 200,000 sequences also revealed the occurrence of 22 mutations in Spike, including changes in amino acids E484 and N501 corresponding to mutations identified in Alpha and Beta [59]. It has been hence been proposed than nAb-based therapeutics could amplify mutations induced by remdesivir [3]. In this regard, Table 4 shows that many of the $\mathrm{mAb}$ - or CCP-associated mutations emerged in individuals who were or had been treated with remdesivir (but neither mAbs nor (CP), consistent with the notion that antiviral therapy could potentiate the emergence of antibody-resistance mutations.

\section{Conclusion}

In summary, our survey of the available mutational data show that escape variants associated with $\mathrm{mAb}$ and CCP therapy manifest different type of mutations. For mAbs most mutations are single amino acid replacements in the RBD domain, while most variants eliciting in patients treated with CCP exhibited amino acid deletions. In fact, it is noteworthy that RBD mutations were relatively rare in CCP escape variants. Although the numbers are relatively small, which suggests cation in making generalizations, this dichotomy in geography of $\mathrm{mAb}$ and CCP mutations could reflect the fact that mAbs target a single epitope where the mAb-antigen interaction can be significantly altered by single amino acid changes while CCP targets many epitopes and has several mechanisms of action, such that evading polyclonal antibody immunity is likely to require much larger Spike protein structural changes. Despite the relatively small set of variants for which there is molecular data available, the large variation of molecular solutions that allow SARS-CoV-2 to escape antibodymediated protection is striking and suggest the need for continued vigilance in genomic surveillance, especially in cases refractory to therapy.

We declare we don't have any conflict of interest related to this manuscript.

\section{References}

1. Van Egeren, D.; Novokhodko, A.; Stoddard, M.; Tran, U.; Zetter, B.; Rogers, M.; Pentelute, B. L.; Carlson, J. M.; Hixon, M. S.; Joseph-McCarthy, D.; Chakravarty, A., Risk of evolutionary escape from neutralizing antibodies targeting SARS-CoV-2 spike protein. 2020, 2020.11.17.20233726.

2. Landis, J.; Moorad, R.; Pluta, L. J.; Caro-Vegas, C.; McNamara, R. P.; Eason, A. B.; Bailey, A.; Villamor, F. C. S.; Juarez, A.; Wong, J. P.; Yang, B.; Broussard, G. S.; Damania, B.; Dittmer, D., 
Intra-host evolution provides for continuous emergence of SARS-CoV-2 variants. 2021, 2021.05.08.21256775.

3. Colson, P.; Devaux, C. A.; Lagier, J. C.; Gautret, P.; Raoult, D., A Possible Role of Remdesivir and Plasma Therapy in the Selective Sweep and Emergence of New SARS-CoV-2 Variants. Journal of clinical medicine 2021, 10, (15).

4. Kabinger, F.; Stiller, C.; Schmitzová, J.; Dienemann, C.; Hillen, H. S.; Höbartner, C.; Cramer, P., Mechanism of molnupiravir-induced SARS-CoV-2 mutagenesis. 2021, 2021.05.11.443555.

5. Starr, T. N.; Greaney, A. J.; Hilton, S. K.; Ellis, D.; Crawford, K. H. D.; Dingens, A. S.; Navarro, M. J.; Bowen, J. E.; Tortorici, M. A.; Walls, A. C.; King, N. P.; Veesler, D.; Bloom, J. D., Deep Mutational Scanning of SARS-CoV-2 Receptor Binding Domain Reveals Constraints on Folding and ACE2 Binding. Cell 2020, 182, (5), 1295-1310.e20.

6. Greaney, A. J.; Starr, T. N.; Gilchuk, P.; Zost, S. J.; Binshtein, E.; Loes, A. N.; Hilton, S. K.; Huddleston, J.; Eguia, R.; Crawford, K. H. D.; Dingens, A. S.; Nargi, R. S.; Sutton, R. E.; Suryadevara, N.; Rothlauf, P. W.; Liu, Z.; Whelan, S. P. J.; Carnahan, R. H.; Crowe, J. E., Jr.; Bloom, J. D., Complete Mapping of Mutations to the SARS-CoV-2 Spike Receptor-Binding Domain that Escape Antibody Recognition. Cell host \& microbe 2020.

7. Javanmardi, K.; Chou, C.-W.; Terrace, C.; Annapareddy, A.; Kaoud, T. S.; Guo, Q.; Lutgens, J.; Zorkic, H.; Horton, A. P.; Gardner, E. C.; Nguyen, G.; Boutz, D. R.; Goike, J.; Voss, W. N.; Kuo, H.-C.; Dalby, K. N.; Gollihar, J. D.; Finkelstein, I. J., Rapid characterization of spike variants via mammalian cell surface display. 2021, 2021.03.30.437622.

8. Starr, T. N.; Greaney, A. J.; Addetia, A.; Hannon, W. W.; Choudhary, M. C.; Dingens, A. S.; Li, J. Z.; Bloom, J. D., Prospective mapping of viral mutations that escape antibodies used to treat COVID-19. Science 2021, eabf9302.

9. Starr, T. N.; Greaney, A. J.; Dingens, A. S.; Bloom, J. D., Complete map of SARS-CoV-2 RBD mutations that escape the monoclonal antibody LY-CoV555 and its cocktail with LY-CoV016. Cel Reports Medicine 2021, 2, (4), 100255.

10. Garrett, M. E.; Galloway, J.; Chu, H. Y.; Itell, H. L.; Stoddard, C. I.; Wolf, C. R.; Logue, J. K.; McDonald, D.; Matsen, F. A.; Overbaugh, J., High resolution profiling of pathways of escape for SARS-CoV-2 spike-binding antibodies. bioRxiv 2020.

11. Andreano, E.; Piccini, G.; Licastro, D.; Casalino, L.; Johnson, N. V.; Paciello, I.; Dal Monego, S.; Pantano, E.; Manganaro, N.; Manenti, A.; Manna, R.; Casa, E.; Hyseni, I.; Benincasa, L.; Montomoli, E.; Amaro, R. E.; McLellan, J. S.; Rappuoli, R., SARS-CoV-2 escape in vitro from a highly neutralizing COVID-19 convalescent plasma. Proceedings of the National Academy of Sciences of the United States of America 2020, 118, (36), e2103154118.

12. Wang, Z.; Schmidt, F.; Weisblum, Y.; Muecksch, F.; Barnes, C. O.; Finkin, S.; SchaeferBabajew, D.; Cipolla, M.; Gaebler, C.; Lieberman, J. A.; Yang, Z.; Abernathy, M. E.; HueyTubman, K. E.; Hurley, A.; Turroja, M.; West, K. A.; Gordon, K.; Millard, K. G.; Ramos, V.; Silva, J. D.; Xu, J.; Colbert, R. A.; Patel, R.; Dizon, J. P.; Unson-O'Brien, C.; Shimeliovich, I.; Gazumyan, A.; Caskey, M.; Bjorkman, P. J.; Casellas, R.; Hatziioannou, T.; Bieniasz, P. D.; Nussenzweig, M. C. mRNA vaccine-elicited antibodies to SARS-CoV-2 and circulating variants. https://www.biorxiv.org/content/biorxiv/early/2021/01/19/2021.01.15.426911.full.pdf

13. Casadevall, A.; Henderson, J.; Joyner, M.; Pirofski, L.-a., SARS-Cov2 variants and convalescent plasma: reality, fallacies, and opportunities. The Journal of clinical investigation 2021.

14. Valesano, A. L.; Rumfelt, K. E.; Dimcheff, D. E.; Blair, C. N.; Fitzsimmons, W. J.; Petrie, J. G.; Martin, E. T.; Lauring, A. S., Temporal dynamics of SARS-CoV-2 mutation accumulation within and across infected hosts. 2021, 2021.01.19.427330.

15. Page, M. J.; McKenzie, J. E.; Bossuyt, P. M.; Boutron, I.; Hoffmann, T. C.; Mulrow, C. D.; Shamseer, L.; Tetzlaff, J. M.; Akl, E. A.; Brennan, S. E.; Chou, R.; Glanville, J.; Grimshaw, J. M.; Hróbjartsson, A.; Lalu, M. M.; Li, T.; Loder, E. W.; Mayo-Wilson, E.; McDonald, S.; McGuinness, L. A.; Stewart, L. A.; Thomas, J.; Tricco, A. C.; Welch, V. A.; Whiting, P.; Moher, 
D., The PRISMA 2020 statement: an updated guideline for reporting systematic reviews. 2021, 372, n71.

16. Walls, A. C.; Park, Y. J.; Tortorici, M. A.; Wall, A.; McGuire, A. T.; Veesler, D., Structure, Function, and Antigenicity of the SARS-CoV-2 Spike Glycoprotein. Cell 2020, 181, (2), 281292.e6.

17. Ju, B.; Zhang, Q.; Ge, J.; Wang, R.; Sun, J.; Ge, X.; Yu, J.; Shan, S.; Zhou, B.; Song, S.; Tang, X.; Yu, J.; Lan, J.; Yuan, J.; Wang, H.; Zhao, J.; Zhang, S.; Wang, Y.; Shi, X.; Liu, L.; Zhao, J.; Wang, X.; Zhang, Z.; Zhang, L., Human neutralizing antibodies elicited by SARS-CoV-2 infection. Nature 2020, 584, (7819), 115-119.

18. The PyMOL Molecular Graphics System, Version 2.4.1 Schrödinger, LLC.

19. Wang, P.; Nair, M. S.; Lihong, L.; Iketani, S.; Luo, Y.; Guo, Y.; Wang, M.; Yu, J.; Zhang, B.; Kwong, P. D.; Graham, B. S.; Mascola, J. R.; Chang, J. Y.; Yin, M. T.; Sobieszczyk, M. E.; Kyratsous, C. A.; Shapiro, L.; Sheng, Z.; Huang, Y.; Ho, D. D., Antibody resistance of SARS-CoV2 variants B.1.351 and B.1.1.7. Nature 2021, 593, 130-135.

20. Choi, B.; Choudhary, M. C.; Regan, J.; Sparks, J. A.; Padera, R. F.; Qiu, X.; Solomon, I. H.; Kuo, H.-H.; Boucau, J.; Bowman, K.; Adhikari, U. D.; Winkler, M. L.; Mueller, A. A.; Hsu, T. Y.-T.; Desjardins, M.; Baden, L. R.; Chan, B. T.; Walker, B. D.; Lichterfeld, M.; Brigl, M.; Kwon, D. S.; Kanjilal, S.; Richardson, E. T.; Jonsson, A. H.; Alter, G.; Barczak, A. K.; Hanage, W. P.; Yu, X. G.; Gaiha, G. D.; Seaman, M. S.; Cernadas, M.; Li, J. Z., Persistence and Evolution of SARS-CoV-2 in an Immunocompromised Host. 2020, 383, (23), 2291-2293.

21. Clark, S. A.; Clark, L. E.; Pan, J.; Coscia, A.; McKay, L. G. A.; Shankar, S.; Johnson, R. I.; Brusic, V.; Choudhary, M. C.; Regan, J.; Li, J. Z.; Griffiths, A.; Abraham, J., SARS-CoV-2 evolution in an immunocompromised host reveals shared neutralization escape mechanisms. Cell 2021, 184, (10), 2605-2617.e18.

22. Choudhary, M. C.; Chew, K. W.; Deo, R.; Flynn, J. P.; Regan, J.; Crain, C. R.; Moser, C.; Hughes, M.; Ritz, J.; Ribeiro, R. M.; Ke, R.; Dragavon, J. A.; Javan, A. C.; Nirula, A.; Klekotka, P.; Greninger, A. L.; Fletcher, C. V.; Daar, E. S.; Wohl, D. A.; Eron, J. J.; Currier, J. S.; Parikh, U. M.; Sieg, S. F.; Perelson, A. S.; Coombs, R. W.; Smith, D. M.; Li, J. Z., Emergence of SARS-CoV-2 Resistance with Monoclonal Antibody Therapy. medRxiv 2021.

23. Truffot, A.; Andreani, J.; Le Marechal, M.; Caporossi, A.; Epaulard, O.; Poignard, P.; Sylvie, L., SARS-CoV-2 Variants in Immunocompromised Patient Given Antibody Monotherapy. Emerging infectious diseases 2021, 27, (10).

24. Lohr, B.; Niemann, D.; Verheyen, J., Bamlanivimab treatment leads to rapid selection of immune escape variant carrying E484K mutation in a B.1.1.7 infected and immunosuppressed patient. Clinical infectious diseases : an official publication of the Infectious Diseases Society of America 2021.

25. Jensen, B.; Luebke, N.; Feldt, T.; Keitel, V.; Brandenburger, T.; Kindgen-Milles, D.; Lutterbeck, M.; Freise, N. F.; Schoeler, D.; Haas, R.; Dilthey, A.; Adams, O.; Walker, A.; Timm, J.; Luedde, T., Emergence of the E484K mutation in SARS-COV-2-infected immunocompromised patients treated with bamlanivimab in Germany. The Lancet Regional Health - Europe 2021, 8.

26. Bronstein, Y.; Adler, A.; Katash, H.; Halutz, O.; Y, H.; Levytskyi, K., Evolution of spike mutations following antibody treatment in two immunocompromised patients with persistent COVID-19 infection. Journal of medical virology 2021.

27. Sabin, A. P.; Richmond, C. S.; Kenny, P. A., Acquisition and onward transmission of a SARSCoV-2 E484K variant among household contacts of a bamlanivimab-treated patient. 2021, 2021.10.02.21264415.

28. Peiffer-Smadja, N.; Bridier-Nahmias, A.; Ferré, V. M.; Charpentier, C.; Garé, M.; Rioux, C.; Allemand, A.; Lavallée, P.; Ghosn, J.; Kramer, L.; Descamps, D.; Yazdanpanah, Y.; Visseaux, B., Emergence of E484K Mutation Following Bamlanivimab Monotherapy among High-Risk Patients Infected with the Alpha Variant of SARS-CoV-2. Viruses 2021, 13, (8). 
29. Gottlieb, R. L.; Nirula, A.; Chen, P.; Boscia, J.; Heller, B.; Morris, J.; Huhn, G.; Cardona, J.; Mocherla, B.; Stosor, V.; Shawa, I.; Kumar, P.; Adams, A. C.; Van Naarden, J.; Custer, K. L.; Durante, M.; Oakley, G.; Schade, A. E.; Holzer, T. R.; Ebert, P. J.; Higgs, R. E.; Kallewaard, N. L.; Sabo, J.; Patel, D. R.; Klekotka, P.; Shen, L.; Skovronsky, D. M., Effect of Bamlanivimab as Monotherapy or in Combination With Etesevimab on Viral Load in Patients With Mild to Moderate COVID-19: A Randomized Clinical Trial. JAMA 2021, 325, (7), 632-644.

30. Focosi, D.; Novazzi, F.; Genoni, A.; Dentali, F.; Dalla Gasperina, D.; Baj, A.; Maggi, F., Daniele Focosi, Federica Novazzi, Angelo Genoni, Francesco Dentali, Daniela Dalla gasperina, Andreina Baj, Fabrizio Maggi. 2021.

31. Guigon, A.; Faure, E.; Lemaire, C.; Chopin, M.; Tinez, C.; Assaf, A.; Lazrek, M.; Hober, D.; Bocket, L.; Engelmann, I.; Kazali Alidjinou, E., Emergence of Q493R mutation in SARS-CoV-2 spike protein during bamlanivimab/etesevimab treatment and resistance to viral clearance. $J$ Infect 2021, S0163-4453, (21), 00435-7.

32. Vellas, C.; Del Bello, A.; Alexa, D.; Steinmeyer, Z.; Tribaudeau, L.; Ranger, N.; Jeanne, N.; Martin-Blondel, G.; Delobel, P.; Kamar, N.; Izopet, J., Influence of neutralizing monoclonal antibodies on the SARS-CoV-2 quasispecies in patients with COVID-19. Clin Microb Infect 2021.

33. Pommeret, F.; Colomba, J.; Bigenwald, C.; Laparra, A.; Bockel, S.; Bayle, A.; Michot, J. M.; Hueso, T.; Albiges, L.; Tiberghien, P.; Marot, S.; Jary, A.; Lacombe, K.; Barlesi, F.; Griscelli, F.; Colomba, E., Bamlanivimab+ etesevimab therapy induces SARS-CoV-2 immune escape mutations and secondary clinical deterioration in COVID-19 patients with B-cell malignancies. Annals of Oncology 2021.

34. Avanzato, V. A.; Matson, M. J.; Seifert, S. N.; Pryce, R.; Williamson, B. N.; Anzick, S. L.; Barbian, K.; Judson, S. D.; Fischer, E. R.; Martens, C.; Bowden, T. A.; de Wit, E.; Riedo, F. X.; Munster, V. J., Case Study: Prolonged Infectious SARS-CoV-2 Shedding from an Asymptomatic Immunocompromised Individual with Cancer. Cell 2020.

35. Hensley, M. K.; Bain, W. G.; Jacobs, J.; Nambulli, S.; Parikh, U.; Cillo, A.; Staines, B.; Heaps, A.; Sobolewski, M. D.; Rennick, L. J.; Macatangay, B. J. C.; Klamar-Blain, C.; Kitsios, G. D.; Methé, B.; Somasundaram, A.; Bruno, T.; Cardello, C.; Shan, F.; Workman, C.; Ray, P.; Ray, A.; Lee, J.; Sethi, R.; Schwarzmann, W. E.; Ladinsky, M. S.; Bjorkman, P. J.; Vignali, D. A.; Duprex, W. P.; Agha, M. E.; Mellors, J. W.; McCormick, K. D.; Morris, A.; Haidar, G., Intractable COVID-19 and Prolonged SARS-CoV-2 Replication in a CAR-T-cell Therapy Recipient: A Case Study. Clinical infectious diseases : an official publication of the Infectious Diseases Society of America 2021.

36. Kemp, S. A.; Collier, D. A.; Datir, R.; Gayed, S.; Jahun, A.; Hosmillo, M.; Ferreira, I. A.; ReesSpear, C.; Mlcochova, P.; Lumb, I. U.; Roberts, D.; Chandra, A.; Temperton, N.; Sharrocks, K.; Blane, E.; Briggs, J. A.; Smith, K. G.; Bradley, J. R.; Smith, C.; Goldstein, R.; Goodfellow, I. G.; Smielewska, A.; Skittrall, J. P.; Gouliouris, T.; Gkrania-Klotsas, E.; Illingworth, C. J.; McCoy, L. E.; Gupta, R. K., Neutralising antibodies in Spike mediated SARS-CoV-2 adaptation. Nature 2020, 2020.12.05.20241927.

37. Truong, T. T.; Ryutov, A.; Pandey, U.; Yee, R.; Goldberg, L.; Bhojwani, D.; Aguayo-Hiraldo, P.; Pinsky, B. A.; Pekosz, A.; Shen, L.; Boyd, S. D.; Wirz, O. F.; Roltgen, K.; Bootwalla, M.; Maglinte, D. T.; Ostrow, D.; Ruble, D.; Han, J. H.; Biegel, J. A.; Li, M.; Huang, C.; Sahoo, M. K.; Pannaraj, P. S.; O'Gorman, M.; Judkins, A. R.; Gai, X.; Dien Bard, J., Persistent SARS-CoV-2 infection and increasing viral variants in children and young adults with impaired humoral immunity. EBioMedicine 2021, 67, 103355.

38. Chen, L.; Zody, M. C.; Mediavilla, J. R.; Cunningham, M. H.; Composto, K.; Chow, K. F.; Kordalewska, M.; Corvelo, A.; Oschwald, D. M.; Fennessey, S.; Zetkulic, M.; Dar, S.; Kramer, Y.; Mathema, B.; Maniatis, T.; Perlin, D. S.; Kreiswirth, B. N., Emergence of multiple SARSCoV-2 antibody escape variants in an immunocompromised host undergoing convalescent plasma treatment. $m S$ phere 2021, 6, (4), e0048021. 
39. Monrad, I.; Sahlertz, S. R.; Nielsen, S. S. F.; Pedersen, L.; Petersen, M. S.; Kobel, C. M.; Tarpgaard, I. H.; Storgaard, M.; Mortensen, K. L.; Schleimann, M. H.; Tolstrup, M.; Vibholm, L. K., Persistent Severe Acute Respiratory Syndrome Coronavirus 2 Infection in Immunocompromised Host Displaying Treatment Induced Viral Evolution. Open forum infectious diseases 2021, 8, (7), ofab295.

40. Baang, J. H.; Smith, C.; Mirabelli, C.; Valesano, A. L.; Manthei, D. M.; Bachman, M. A.; Wobus, C. E.; Adams, M.; Washer, L.; Martin, E. T.; Lauring, A. S., Prolonged Severe Acute Respiratory Syndrome Coronavirus 2 Replication in an Immunocompromised Patient. J Infect Dis 2021, 223, (1), 23-27.

41. Nussenblatt, V.; Roder, A.; Das, S.; de Wit, E.; Youn, J.-H.; Banakis, S.; Muchegian, A.; Mederos, C.; Wang, W.; Chung, M.; Perez-Perez, L.; Palmore, T.; Brudno, J.; Kochenderfer, J.; Ghedin, E., Year-long COVID-19 infection reveals within-host evolution of SARS-CoV-2 in a patient with B cell depletion. 2021, 2021.10.02.21264267.

42. Khatamzas, E.; Rehn, A.; Muenchhoff, M.; Hellmuth, J.; Gaitzsch, E.; Weiglein, T.; Georgi, E.; Scherer, C.; Stecher, S.; Weigert, O.; Girl, P.; Zange, S.; Keppler, O. T.; Stemmler, J.; von Bergwelt-Baildon, M.; Wölfel, R.; Antwerpen, M., Emergence of multiple SARS-CoV-2 mutations in an immunocompromised host. 2021, 2021.01.10.20248871.

43. Sepulcri, C.; Dentone, C.; Mikulska, M.; Bruzzone, B.; Lai, A.; Fenoglio, D.; Bozzano, F.; Bergna, A.; Parodi, A.; Altosole, T.; Delfino, E.; Bartalucci, G.; Orsi, A.; Di Biagio, A.; Zehender, G.; Ballerini, F.; Bonora, S.; De Palma, R.; Silvestri, G.; De Maria, A.; Bassetti, M., The longest persistence of viable SARS-CoV-2 with recurrence of viremia and relapsing symptomatic COVID-19 in an immunocompromised patient - a case study. Open forum infectious diseases 2021, ofab217, 2021.01.23.21249554.

44. Mendes-Correa, M. C.; Ghilardi, F.; Salomao, M. C.; Villas-Boas, L. S.; Vincente de Paula, A.; Tozetto-Mendoza, T. R.; Freire, W.; Sales, F. C. d. S.; Romano, C. M.; Claro, I. M.; de Souza, L. M.; Ramos, J. F.; Paiao, H. G. d. O.; Szor, R. S., SARS-CoV-2 shedding, infectivity and evolution in an immunocompromised adult patient. 2021, 2021.06.11.21257717.

45. Bazykin, G.; Stanevich, O.; Danilenko, D.; Fadeev, A.; Komissarova, K.; Ivanova, A.; Sergeeva, M.; Safina, K.; Nabieva, E.; Klink, G.; Garushyants, S.; Zabutova, J.; Kholodnaia, A.; Skorokhod, I.; Ryabchikova, V.; Komissarov, A.; Lioznov, D. Emergence of Y453F and $\triangle 69-70 H V$ mutations in a lymphoma patient with long-term COVID-19. https://virological.org/t/emergence-ofy453f-and-69-70hv-mutations-in-a-lymphoma-patient-with-long-term-covid-19/580

46. Borges, V.; Isidro, J.; Cunha, M.; Cochicho, D.; Martins, L.; Banha, L.; Figueiredo, M.; Rebelo, L.; Trindade, M.; Duarte, S.; Vieira, L.; Alves, M.; Costa, I.; Guiomar, R.; Santos, M.; CortêReal, R.; Dias, A.; Póvoas, D.; Cabo, J.; Figueiredo, C.; Manata, M.; Maltez, F.; da Silva, M.; Gomes, J., Long-term evolution of SARS-CoV-2 in an immunocompromised patient with nonHodgkin lymphoma. mSphere 2021, e0024421.

47. Karim, F.; Moosa, M. Y.; Gosnell, B.; Sandile, C.; Giandhari, J.; Pillay, S.; Tegally, H.; Wilkinson, E.; San, E. J.; Msomi, N.; Mlisana, K.; Khan, K.; Bernstein, M.; Manickchund Nithendra, N.; Singh, L.; Ramphal, U.; Hanekom, W.; Lessells, R. J.; Sigal, A.; de Oliveira, T., Persistent SARSCoV-2 infection and intra-host evolution in association with advanced HIV infection. 2021, 2021.06.03.21258228.

48. Kavanagh Williamson, M.; Hamilton, F.; Hutchings, S.; Pymont, H. M.; Hackett, M.; Arnold, D.; Maskell, N.; MacGowan, A. P.; Albur, m.; Jenkins, M.; Heys, I.; Knapper, F.; Elsayed, M.; Milligan, R.; Muir, P.; Vipond, B.; Matthews, D. A.; Moran, E.; Davidson, A. D. D., Chronic SARS-CoV-2 infection and viral evolution in a hypogammaglobulinaemic individual. 2021, 2021.05.31.21257591.

49. Weigang, S.; Fuchs, J.; Zimmer, G.; Schnepf, D.; Kern, L.; Beer, J.; Luxenburger, H.; Ankerhold, J.; Falcone, V.; Kemming, J.; Hofmann, M.; Thimme, R.; Neumann-Haefelin, C.; Ulferts, S.; Grosse, R.; Hornuss, D.; Tanriver, Y.; Rieg, S.; Wagner, D.; Huzly, D.; Schwemmle, M.; 
Panning, M.; Kochs, G., Within-host evolution of SARS-CoV-2 in an immunosuppressed COVID-19 patient: a source of immune escape variants. 2021, 2021.04.30.21256244.

50. Lee, C. Y.; Shah, M. K.; Hoyos, D.; Solovyov, A.; Douglas, M.; Taur, Y.; Maslak, P. G.; Babady, N. E.; Greenbaum, B.; Kamboj, M.; Vardhana, S. A., Prolonged SARS-CoV-2 infection in patients with lymphoid malignancies. 2021, 2021.08.25.21262417.

51. Focosi, D.; Franchini, M.; Pirofski, L. A.; Maggi, F.; Casadevall, A., Is SARS-CoV-2 viral clearance in nasopharyngal swabs an appropriate surrogate marker for clinical efficacy of neutralizing antibody-based therapeutics? Rev Med Virol 2021.

52. Copin, R.; Baum, A.; Wloga, E.; Pascal, K. E.; Giordano, S.; Fulton, B. O.; Zhou, A.; Negron, N.; Lanza, K.; Chan, N.; Coppola, A.; Chiu, J.; Ni, M.; Atwal, G. S.; Romero Hernandez, A.; Saotome, K.; Zhou, Y.; Franklin, M. C.; Hooper, A. T.; McCarthy, S.; Hamon, S.; Hamilton, J. D.; Staples, H. M.; Alfson, K.; Carrion, R.; Ali, S.; Norton, T.; Somersan-Karakaya, S.; Sivapalasingam, S.; Herman, G. A.; Weinreich, D. M.; Lipsich, L.; Stahl, N.; Murphy, A. J.; Yancopoulos, G. D.; Kyratsous, C. A., REGEN-COV protects against viral escape in preclinical and human studies. bioRxiv [Preprint] 2021, 2021.03.10.434834.

53. Baum, A.; Fulton, B. O.; Wloga, E.; Copin, R.; Pascal, K. E.; Russo, V.; Giordano, S.; Lanza, K.; Negron, N.; Ni, M.; Wei, Y.; Atwal, G. S.; Murphy, A. J.; Stahl, N.; Yancopoulos, G. D.; Kyratsous, C. A., Antibody cocktail to SARS-CoV-2 spike protein prevents rapid mutational escape seen with individual antibodies. 2020, 369, (6506), 1014-1018.

54. Harvey, W. T.; Carabelli, A. M.; Jackson, B.; Gupta, R. K.; Thomson, E. C.; Harrison, E. M.; Ludden, C.; Reeve, R.; Rambaut, A.; Peacock, S. J.; Robertson, D. L.; Consortium, C.-G. U., SARS-CoV-2 variants, spike mutations and immune escape. Nature Reviews Microbiology 2021, 19, (7), 409-424.

55. Aydillo, T.; Gonzalez-Reiche, A. S.; Aslam, S.; van de Guchte, A.; Khan, Z.; Obla, A.; Dutta, J.; van Bakel, H.; Aberg, J.; García-Sastre, A.; Shah, G.; Hohl, T.; Papanicolaou, G.; Perales, M.-A.; Sepkowitz, K.; Babady, N. E.; Kamboj, M., Shedding of Viable SARS-CoV-2 after Immunosuppressive Therapy for Cancer. 2020, 383, (26), 2586-2588.

56. McCarthy, K. R.; Rennick, L. J.; Nambulli, S.; Robinson-McCarthy, L. R.; Bain, W. G.; Haidar, G.; Duprex, W. P., Recurrent deletions in the SARS-CoV-2 spike glycoprotein drive antibody escape. Science 2021, 371, (6534), 1139-1142.

57. Voloch, C. M.; da Silva Francisco Jr, R.; de Almeida, L. G. P.; Brustolini, O. J.; Cardoso, C. C.; Gerber, A. L.; Guimarães, A. P. d. C.; Leitão, I. d. C.; Mariani, D.; Ota, V. A.; Lima, C. X.; Teixeira, M. M.; Dias, A. C. F.; Galliez, R. M.; Faffe, D. S.; Pôrto, L. C.; Aguiar, R. S.; Castiñeira, T. M. P. P.; Ferreira, O. C.; Tanuri, A.; de Vasconcelos, A. T. R., Intra-host evolution during SARS-CoV-2 prolonged infection. Virus Evolution 2021, 7, (2).

58. Singh, V.; Fedeles, B. I.; Essigmann, J. M., Role of tautomerism in RNA biochemistry. RNA (New York, N.Y.) 2015, 21, (1), 1-13.

59. Szemiel, A. M.; Merits, A.; Orton, R. J.; MacLean, O.; Pinto, R. M.; Wickenhagen, A.; Lieber, G.; Turnbull, M. L.; Wang, S.; Mair, D.; da Silva Filipe, A.; Willett, B. J.; Wilson, S. J.; Patel, A. H.; Thomson, E. C.; Palmarini, M.; Kohl, A.; Stewart, M. E., <em $>$ In vitro</em> evolution of Remdesivir resistance reveals genome plasticity of SARS-CoV-2. 2021, 2021.02.01.429199. 